\title{
Bursting-induced Epileptiform EPSPs in Slices of Piriform Cortex Are Generated by Deep Cells
}

\author{
William H. Hoffman' ${ }^{1}$ and Lewis B. Haberly ${ }^{1,2}$ \\ 'Neuroscience Training Program and '2Department of Anatomy, University of Wisconsin, Madison, Wisconsin 53706
}

\begin{abstract}
Previous study revealed that bursting activity generated by a variety of means in slices of piriform cortex induces persistent epileptiform EPSPs in superficial pyramidal cells by an NMDA-dependent process. The present study was undertaken to test the hypothesis that the observed epileptiform EPSPs in superficial pyramidal cells are driven by deep cells. This hypothesis was suggested by recent findings from in vitro studies of the properties of deep cells and in vivo studies indicating that the deep part of the piriform cortex or neighboring deep structures are involved in the generation of seizure activity in animal models of epilepsy. Results from simultaneous cell-pair recordings, examination of subdivided slices, and local application of excitatory and inhibitory agents provided strong evidence in support of this hypothesis. It was concluded that the endopiriform nucleus, a collection of cells immediately deep to the piriform cortex, plays a central role in generation, but that cells in the deep part of layer III and the claustrum may also contribute. Furthermore, it was found that generation of prolonged ictal-like activity only occurs in slices of piriform cortex in which the endopiriform nucleus is present. Implications of these findings for epileptogenesis are discussed.
\end{abstract}

Evidence from animal models of epilepsy suggests that the piriform (olfactory) cortex is highly susceptible to epileptogenesis. In kindled rats, the majority of interictal spikes originate in the piriform cortex regardless of the position of the kindling electrode (Racine et al., 1988). Injection of excitatory amino acid antagonists (Croucher et al., 1988) or a GABA transaminase inhibitor (Stevens et al., 1988) into an area near the deep boundary of the piriform cortex suppresses kindling and kindled seizures, respectively, from stimulation in limbic structures. Furthermore, injection of convulsant drugs at the deep boundary of the piriform cortex evokes generalized seizures in unanesthetized rats at doses that are 20-30 times lower than required in other parts of the forebrain including the hippocampus, amygdala, and neocortex (Piredda and Gale, 1985, 1986; Stevens et al., 1988). Finally, recordings from the piriform cortex of kindled rats in vivo have shown the presence of long-latency excitatory potentials with epileptiform characteristics in response to afferent fiber stimulation (Racine et al., 1988).

A recent study has demonstrated that persistent epileptiform EPSPs (e-EPSPs) can be induced in vitro in piriform cortex by

Received Oct. 15, 1990; revised Dec. 29, 1990; accepted Jan. 31, 1991.

This work was supported by Grant NS19865 from the NINDS (L.B.H.) and from the NIH by Training Grant GM07507 (W.H.H.)

Correspondence should be addressed to Lewis B. Haberly, Department of Anatomy, University of Wisconsin, 1300 University Avenue, Madison, WI 53706.

Copyright (C) 1991 Society for Neuroscience 0270-6474/91/112021-11\$03.00/0 subjecting slices to brief periods of bursting activity (Hoffman and Haberly, 1989). These induced EPSPs in slices are similar to potentials recorded from the piriform cortex of kindled animals in vivo (L. B. Haberly and T. P. Sutula, unpublished observations) and in slices of piriform cortex taken from kindled animals (McIntyre and Wong, 1986; W. H. Hoffman and L. B. Haberly, unpublished observations), suggesting that this preparation may be a useful model for study of the kindling phenomenon. Furthermore, based on the persistent nature and NMDA dependence of the induction process, it may also have implications for understanding plastic processes involved in learning and memory.

In the earlier report (Hoffman and Haberly, 1989), e-EPSPs were studied in superficial pyramidal cells in layer II (analogous to stratum pyramidale in hippocampus). Based on the high susceptibility of the deep part of piriform cortex to epileptogenesis and on the recent finding that deep pyramidal and spiny multipolar cells in the piriform cortex and subjacent endopiriform nucleus have properties that could promote epileptic activity (Tseng and Haberly, 1989a,b), the present study was undertaken to test the hypothesis that bursting-induced EPSPs originate in deeply placed cells. The results have provided evidence that e-EPSPs in superficial pyramidal cells are synaptically driven from deep cells, and suggest that these cells are concentrated in the endopiriform nucleus (considered to be layer IV of piriform cortex in some accounts; see Tseng and Haberly, 1989a).

Preliminary results have been presented in abstract form (Hoffman and Haberly, 1987, 1988).

\section{Materials and Methods}

Rats were anesthetized with ether and decapitated, and a block of brain containing piriform cortex was quickly removed to oxygenated $(95 \%$ $\mathrm{O}_{2}, 5 \% \mathrm{CO}_{2}$ ) bathing medium maintained at $4-10^{\circ} \mathrm{C}$. Slices $0.5 \mathrm{~mm}$ thick were cut in a plane perpendicular to the cortical surface with a Vibratome (Lancer) and transferred to holding chambers, where they recovered at room temperature for at least $2 \mathrm{hr}$. In some experiments, slices were further trimmed 1-5 min after the initial cutting (still at 4$10^{\circ} \mathrm{C}$ ) to isolate specific cortical structures. Such trimming was performed by positioning the submerged slice on a flat piece of wax and lowering a small section of razor blade through the slice at the desired point. Diagrams of the different slice dissections used are shown in Figure 1 (shaded areas were studied). Histological verification of structures included in slice segments was performed in most cases using methods described below.

Recording was carried out on continuously perfused, submerged slices with the chamber described by Tseng and Haberly (1988) at a temperature of $28-31^{\circ} \mathrm{C}$. Use of dark-field illumination allowed visualization of all layers of the piriform cortex and the cell-dense endopiriform nucleus. Standard bathing medium contained (in $\mathrm{mM}$ ) $124.0 \mathrm{NaCl}, 5.0$ $\mathrm{KCl}, 2.4 \mathrm{CaCl}_{2}, 1.3 \mathrm{MgSO}_{4}, 26 \mathrm{NaHCO}_{3}, 1.2 \mathrm{KH}_{2} \mathrm{PO}_{4}$, and $10 \mathrm{D}$-glucose. In some experiments, $\mathrm{CaCl}_{2}$ was $1.5 \mathrm{mM}$ and $\mathrm{KCl}$ was $1.8 \mathrm{~mm}$, for a total $\mathrm{K}^{+}$of $3 \mathrm{~mm}$. Bathing medium with no added $\mathrm{Mg}^{2+}\left(\right.$ termed $\left.0 \mathrm{Mg}^{2+}\right)$ 
A

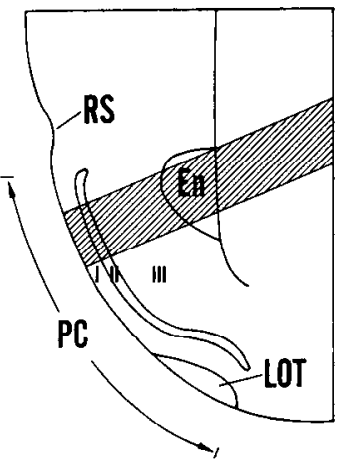

C

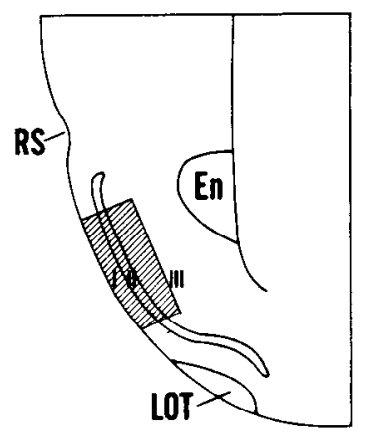

B

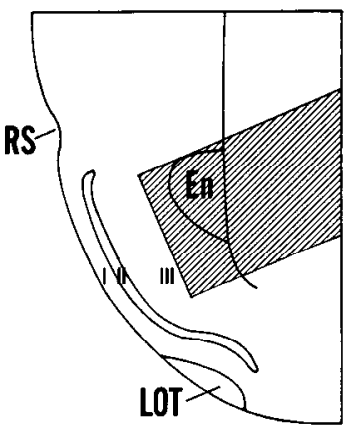

D

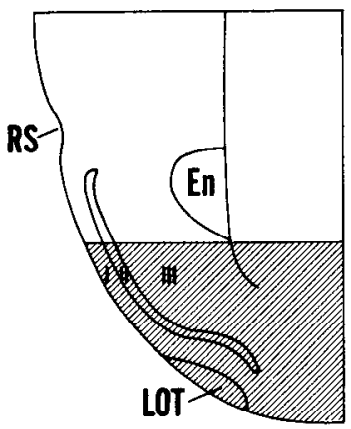

Figure 1. Diagrams of secondary cuts used to isolate specific structures in slices. Shaded regions are the isolated portions that were studied. $A$, "Perpendicular" slice strip containing all layers of piriform cortex and the endopiriform nucleus. $B$, Deep segment containing the endopiriform nucleus and the deep part of layer III of piriform cortex. $C$, Isolated superficial layers of piriform cortex (I, II, and superficial III). $D$, Ventral segment containing all layers of piriform cortex, but no endopiriform nucleus. In addition to piriform cortex and endopiriform nucleus, all segments except that illustrated in $C$ contained portions of subcortical structures (principally striatum). Ventral segments also contained olfactory tubercle. $E n$, endopiriform nucleus; $L O T$, lateral olfactory tract; $P C$, piriform cortex; $R S$, rhinal sulcus. Roman numerals refer to layers in piriform cortex.

was made by replacing $\mathrm{MgSO}_{4}$ with equimolar $\mathrm{Na}_{2} \mathrm{SO}_{4}$. Cells were impaled with glass micropipettes containing $4 \mathrm{M}$ potassium acetate (neutralized) with resistances of 30-80 M $\Omega$. In some experiments, extracellular recordings were obtained with a tungsten microelectrode with a $1-\mathrm{Hz}$ to $10-\mathrm{kHz}$ band pass. Association fibers were stimulated in layer Ib, the deep part of layer III, or the endopiriform nucleus with bipolar tungsten stimulating electrodes at $1 / 6 \mathrm{~Hz}$. Similar synaptically evoked responses were recorded with stimulation at all three locations, presumably because association fibers that originate from pyramidal cells in piriform cortex form a dense plexus that extends through layers Ib-III of the piriform cortex and the endopiriform nucleus. Responses were digitized and analyzed by computer as previously described (Tseng and Haberly, 1988). In some experiments, $\mathrm{L}$-glutamate, $\mathrm{KCl}$, or $\mathrm{CoCl}_{2}$ were locally applied by pressure injection with a PicoPump (World Precision Instruments) using glass micropipettes with tip diameters of $1.5-5 \mu \mathrm{m}$. Solutions were applied by variable-length pulses $(3-1000 \mathrm{msec})$ at 30 psi. $\mathrm{CoCl}_{2}$ and glutamate $(10 \mathrm{~mm})$ were dissolved in $0.9 \% \mathrm{NaCl} ; \mathrm{KCl}$ solutions $(100 \mathrm{~mm})$ were made by replacement of $\mathrm{NaCl}$ in the normal bathing medium. Control injections of $0.9 \% \mathrm{NaCl}$ were also carried out.

In some experiments, the effects of local glutamate, $\mathrm{K}^{+}$, and $\mathrm{Co}^{2+}$ application were systematically mapped. During experiments, injection sites were recorded on detailed drawings or Polaroid photographs of the slice. At the completion of experiments, holes were made with a broken micropipette to mark sites of cell recording or drug application. Slices were then fixed in formaldehyde, sectioned at $80 \mu \mathrm{m}$ with a freezing microtome, mounted on slides, and stained with cresyl violet. Positions
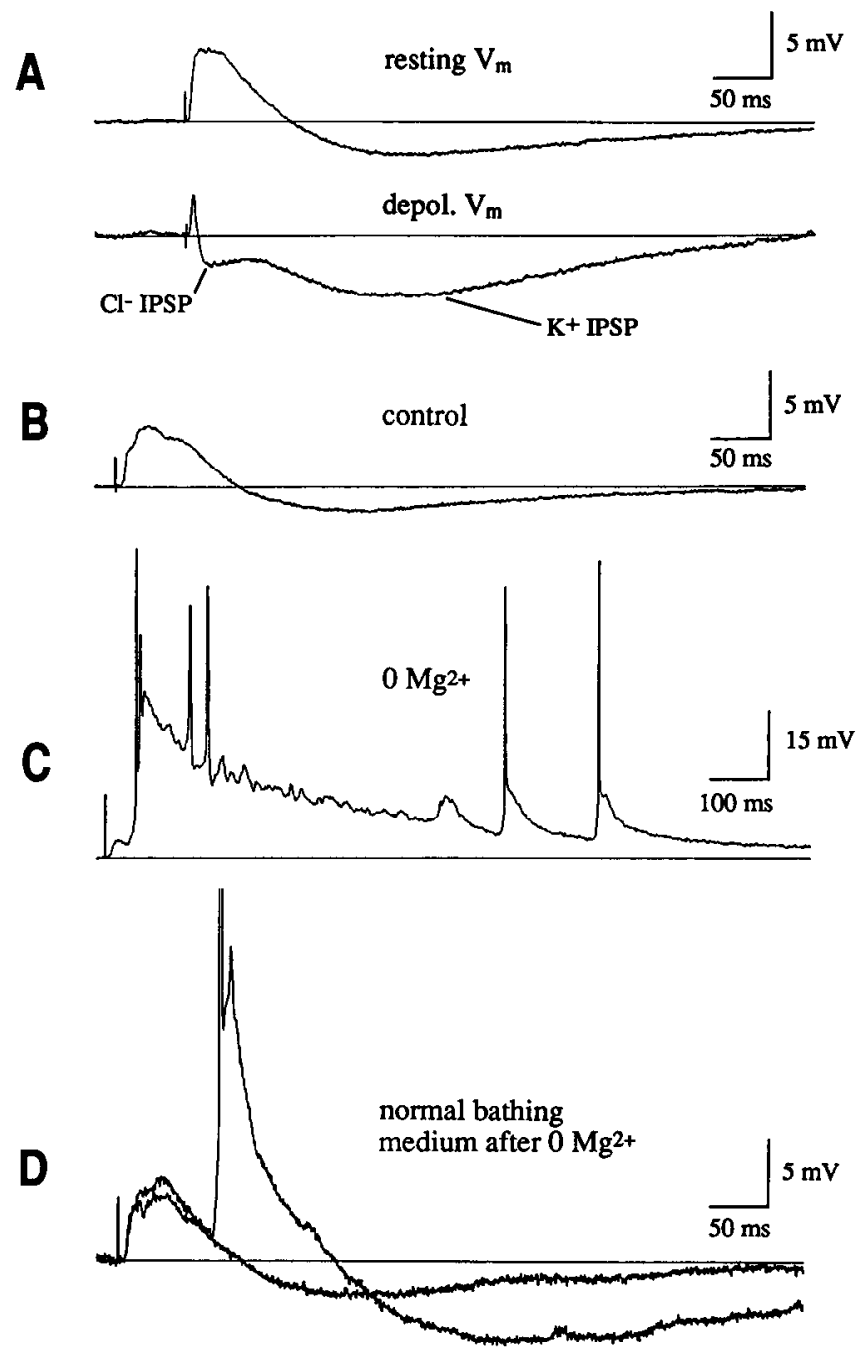

Figure 2. Induction of long-latency e-EPSPs in deep cells by bursting activity. $A$, Typical responses of a deep cell to shock stimulation of association (corticocortical) fibers in layer III. The response consists of an initial monosynaptic EPSP and disynaptic $\mathrm{Cl}^{-}$and $\mathrm{K}^{+}$-mediated IPSPs. $V_{m}=-66 \mathrm{mV}$ for top trace, $-37 \mathrm{mV}$ for bottom trace. $B-D$, Control response, bursting response of deep cell after removal of $\mathrm{Mg}^{2+}$ from the bathing medium, and response $10 \mathrm{~min}$ after return to normal bathing medium, respectively. Stimulation was in layer $\mathrm{Ib}$ with identical shock strengths in $B-D$. Sub- and suprathreshold traces are superimposed in $D$ to illustrate the all-or-none occurrence of the induced EPSP.

of reference holes and other landmarks were used to transfer injection and recording sites to camera lucida drawings of the stained sections for precise correlation with anatomical structures.

Although cells were not identified morphologically, previous studies using similar recording electrodes and injection of Lucifer yellow have shown that cells impaled in layer II are consistently pyramidal, cells in the endopiriform nucleus are consistently spiny multipolar neurons, and cells in layer III are either pyramidal or spiny multipolar neurons (Tseng and Haberly, 1989a). Because cells in the deep part of layer III and the endopiriform nucleus have indistinguishable membrane properties and morphology, and very similar synaptic response properties (Tseng and Haberly, 1989a,b), they will be collectively termed "deep cells."

\section{Results}

Bursting induces e-EPSPS in deep cells

Synaptically mediated responses of deep cells to association fiber stimulation under control conditions (Fig. $2 A$ ) are similar to 


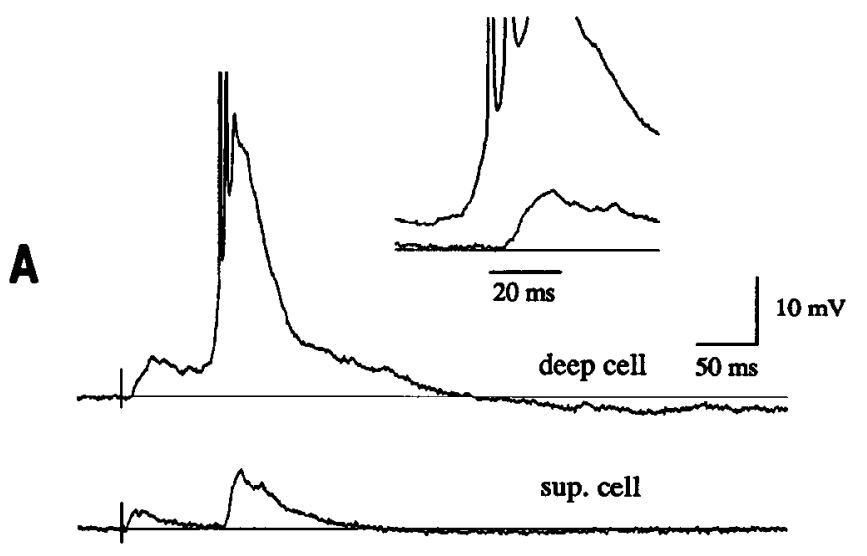

deep cell - subthresh.

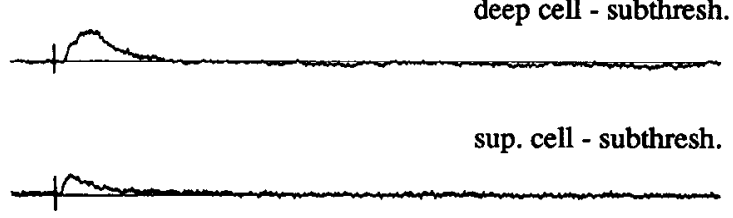

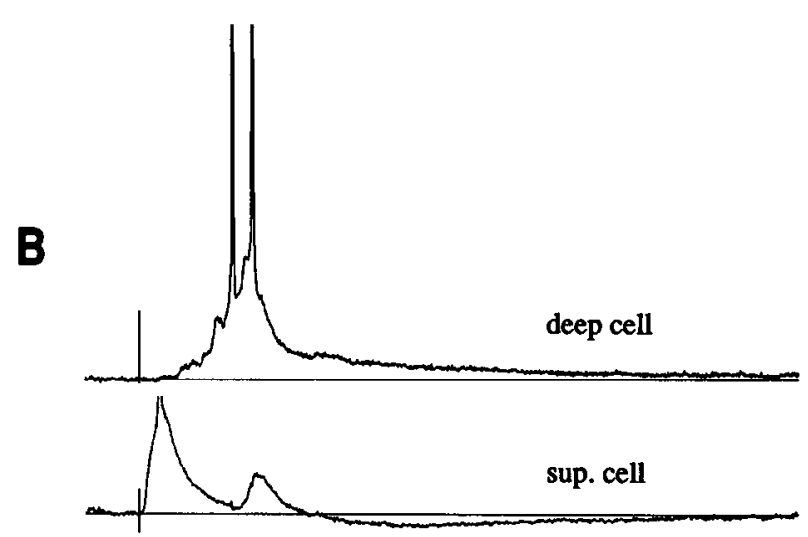

deep cell - subthresh.

sup. cell - subthresh.

Figure 3. e-EPSPs induced by bursting activity are of higher amplitude and occur at shorter latency in deep than in superficial cells. Simultane 15 recordings from two sets of cell pairs in different slices are illustrated in $A$ and $B$. For each set, one cell was a presumed superficial pyramidal sell in layer II (sup. cell), and one, a deep cell in the endopiriform nucleus. Trace pairs at top are responses to shock stimulation of association fibers (layer III in $A$, layer $\mathrm{Ib}$ in $B$ ) at an intensity that was suprathreshold for e-EPSP generation; those at the bottom were subthreshold. The inset in $A$ reveals the temporal relationship between the e-EPSP and evoked action potentials in the deep cell and the e-EPSP in the superficial cell. Note that the e-EPSP in the deep cell in $B$ occurred in isolation without an initial graded EPSP (cf. suprathreshold response at top with subthreshold response at the same stimulus strength at bottom).

those of superficial pyramidal cells, consisting of an early EPSP, a fast $\mathrm{Cl}^{-}$-mediated IPSP, and a slow $\mathrm{K}^{+}$-mediated IPSP as previously described (Tseng and Haberly, 1988, 1989a). Following 2-20 min of bursting evoked by association fiber stimulation at $1 / 6 \mathrm{~Hz}$ in $0 \mathrm{Mg}^{2+}$ (Fig. 2C) and subsequent return to normal medium (Fig. 2D), a high-amplitude, long-latency depolarizing potential was consistently induced as in superficial pyramidal cells by low-strength shock stimulation to layers IIII of the piriform cortex and the endopiriform nucleus (Hoffman and Haberly, 1989). These late depolarizing potentials occurred at a discrete threshold, but were variable in amplitude and waveform, and decreased in latency with increasing shock strength as also observed in superficial cells. Furthermore, late depolarizing potentials in deep cells were epileptiform in character (all-or-none population responses) as in superficial pyramidal cells, because occurrence was perfectly correlated in simultaneously recorded cell pairs (Fig. 3), threshold for their occurrence was the same for all cells impaled in a given slice, and intracellularly recorded late potentials were always correlated with the occurrence of a large extracellular field potential (not shown). As in superficial pyramidal cells (Hoffman and Haberly, 1989), EPSPs underlie the late depolarizing potential. Evidence includes the lack of effect of polarizing current on threshold of these potentials, occurrence in some cells at stimulus strengths subthreshold for the early, graded EPSP (precluding exclusive generation by voltage-dependent currents triggered by the early EPSP; see Fig. $3 B$ ), and a decrease in amplitude at depolarized membrane potentials and increase at hyperpolarized potentials. Both induction and expression occurred at physiological levels of $\mathrm{K}^{+}(3 \mathrm{~mm})$ and $\mathrm{Ca}^{2+}(1.5 \mathrm{~mm})(n=3)$ as well as at the higher concentrations in the standard bathing medium.

Although there were many similarities between e-EPSPs in superficial and decp cclls, there was one striking difference: these potentials were consistently of greater amplitude in deep than in superficial cells. In superficial pyramidal cells, e-EPSPs only rarely evoked action potentials ( $<10 \%$ of cells). In contrast, in greater than $95 \%$ of deep cells, e-EPSPs consistently triggered one or more action potentials (Figs. 2,3). This finding is consistent with the hypothesis that e-EPSPs in superficial cells are synaptically driven by deep cells. To test this hypothesis and to delineate the areas containing cells involved in e-EPSP generation, a number of different experiments were performed involving simultaneous recording from cell pairs, slice dissection, and localized injection of excitatory and inhibitory agents.

\section{e-EPSPs occur at shorter latency in deep cells than in superficial pyramidal cells}

If action potentials evoked by e-EPSPs in dccp cells synaptically mediate e-EPSPs in superficial pyramidal cells, then it can be predicted that they would occur earlier in deep than in superficial cells. Measurements from 10 simultaneously recorded pairs consisting of one deep and one superficial cell confirmed this prediction (Fig. 3). Onset of e-EPSPs in deep cells always preceded those in superficial cells, usually by a sufficient interval that the first action potential in the deep cell preceded the e-EPSP in the superficial cell (Fig. $3 A$, inset). 


\section{Layer II Cell}
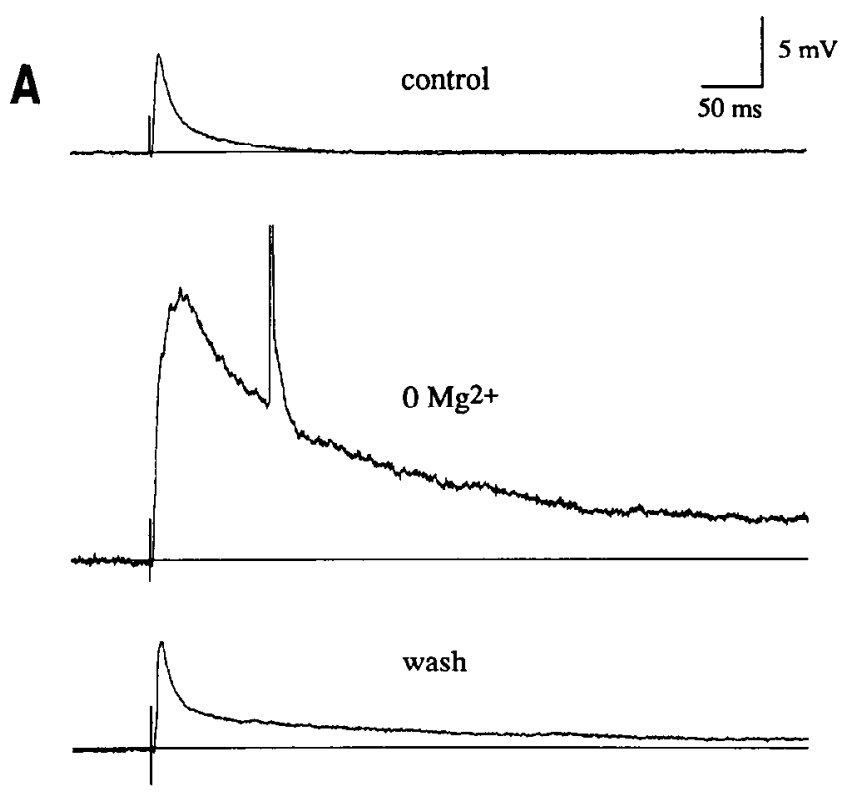

Deep Cell

\section{B}

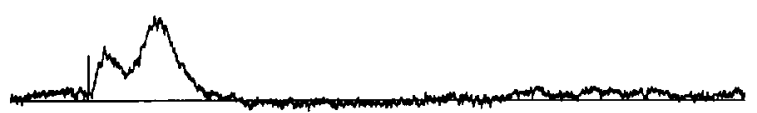

Figure 4. In narrow, perpendicularly oriented slice segments (Fig. 1A), e-EPSPs can be confined to deep cells. $A$, Responses from a layer II cell to stimulation in layer Ib before bursting (control), in $0 \mathrm{Mg}^{2+}$, and after return to normal bathing medium (wash). Note the absence of the induced e-EPSP normally seen in intact slices. No e-EPSP was observed in a second superficial cell in the same slice (not illustrated). $B$, Response from a deep cell in the same slice, recorded subsequently to the response in $A$. Note the presence of a small e-EPSP that was subthreshold for action potential generation.

\section{e-EPSPS can be confined to deep layers in slice fragments}

When thin strips cut from slices of piriform cortex (Fig. 1A) were subjected to bursting activity in $0 \mathrm{Mg}^{2+}$, e-EPSPs were induced only in deep cells in three out of four experiments. These "perpendicular" slice strips (cut normal to the cortical surface) were $0.5-0.75 \mathrm{~mm}$ in width and contained all layers of the piriform cortex and a portion of the underlying endopiriform nucleus and striatum, but no other areas. As illustrated in Figure $4 A$. stimulation of association fibers in $0 \mathrm{Mg}^{2+}$ typically failed to induce e-EPSPs in superficial cells on return to normal bathing medium, despite the fact that e-EPSPs were consistently present in deep cells (Fig. 4B). Moreover, e-EPSPs in deep cells in slice strips were much smaller than in intact slices and frequently failed to evoke action potentials (cf. Figs. $2 D, 3$ with $4 B$ ). In the slice strip in which e-EPSPs did occur in superficial pyramidal cells, they were low in amplitude (2-3 mV), and e-EPSPs in deep cells were larger than in the strips in which abnormal EPSPs were absent in superficial cells.

The findings that e-EPSPs can occur in deep cells alone, and that absence of e-EPSPs in superficial cells is associated with subthreshold e-EPSPs in deep cells, support the hypothesis that these EPSPs originate in deep cells.
Local application of glutamate or $K^{+}$evokes -EPSPS only from deep structures

To further localize the source of e-EPSPs, stimulation was carried out by local injection of glutamate $(10 \mathrm{~mm})$ or $\mathrm{K}^{+}(100 \mathrm{mM}$ $\mathrm{KCl}$ ) through application of pressure to micropipettes. Based on droplet size before placement of injection pipettes in slices, estimated total amount injected was 4-70 pl $(20-50-\mu \mathrm{m}-\mathrm{di}-$ ameter droplets in air). In contrast to shock stimulation, glutamate does not excite "axons of passage" (see, e.g., Christian and Dudek, 1988). Although $\mathrm{K}^{+}$would be expected to depolarize all exposed membranes, results obtained from injection of $\mathrm{K}^{+}$ corresponded closely to those obtained with glutamate.

Responses to pressure injection of glutamate and $\mathrm{K}^{+}$in control slices were consistently graded in amplitude as a function of pulse duration and distance from the recorded cell (Fig. 5A,B). After stimulus-evoked bursting in $0 \mathrm{Mg}^{2+}$ and return to normal bathing medium, brief pulses of glutamate and $\mathrm{K}^{+}$typically evoked a low-amplitude graded potential (Fig. $5 C$, bottom traces), but with increases in pulse duration, a large all-or-none depolarizing potential could be triggered at relatively short latency (Fig. $5 C$, top traces). Adjustment of pulse duration revealed a consistent threshold for this component. Control injections of $0.9 \% \mathrm{NaCl}$ under identical conditions failed to elicit responses of any type. Amplitudes and waveforms of all-ornone depolarizing potentials evoked by glutamate and $\mathrm{K}^{+}$closely resembled those evoked in the same cell by shock stimulation of association fibers (cf. Fig. $5 C, D$ ), indicating that the same "population" process was triggered. As in shock-evoked responses, e-EPSPs triggered by glutamate and $\mathrm{K}^{+}$in deep cells preceded those in simultaneously recorded superficial cells (Fig. $5 C$ ), consistent with deep initiation.

Systematic mapping in eight slices revealed that e-EPSPs were evoked by glutamate or $\mathrm{K}^{+}$only from a restricted deep area (Fig. 6). Histological analysis (Fig. 6C) revealed that this area always included the endopiriform nucleus. In addition, in all slices in which it was present, e-EPSPs were consistently evoked from the claustrum, and in four slices they were occusionally evoked from sites in the ventral agranular insular cortex that overlies the claustrum. Maps obtained with glutamate and $\mathrm{K}^{+}$ were very similar, and in one slice in which mapping with both agents was carried out, they were virtually identical. Outside the above mentioned areas, pulse durations up to 10 times longer failed to evoke e-EPSPs.

\section{Local application of $\mathrm{Co}^{2+}$ to deep layers blocks induced e-EPSPS}

As a further test of the role of deep cells in generation of e-EPSPs, $\mathrm{Ca}^{2+}$ currents were locally reduced by pressure injection of 10 $\mathrm{mM} \mathrm{Co}^{2+}$ from micropipettes. This procedure would be expected to reduce cell excitability by attenuating both synaptic transmission and endogenous excitatory $\mathrm{Ca}^{2+}$ currents that are known to occur in deep cells (Tseng and Haberly, 1989b). In the eight slices studied, injection into the endopiriform nucleus decreased amplitudes and raised thresholds of e-EPSPs, and in some cases blocked generation at the highest shock strengths tested (up to $4 \times$ threshold before injection). A typical experiment with recording from a cell in layer II is illustrated in Figure 7. After injection of $\mathrm{Co}^{2+}$, there was a substantial decrease in amplitude and a small increase in latency of the e-EPSP evoked by association fiber stimulation in layer $\mathrm{Ib}$, followed by a complete disappearance of the e-EPSP. There was no concomitant de- 

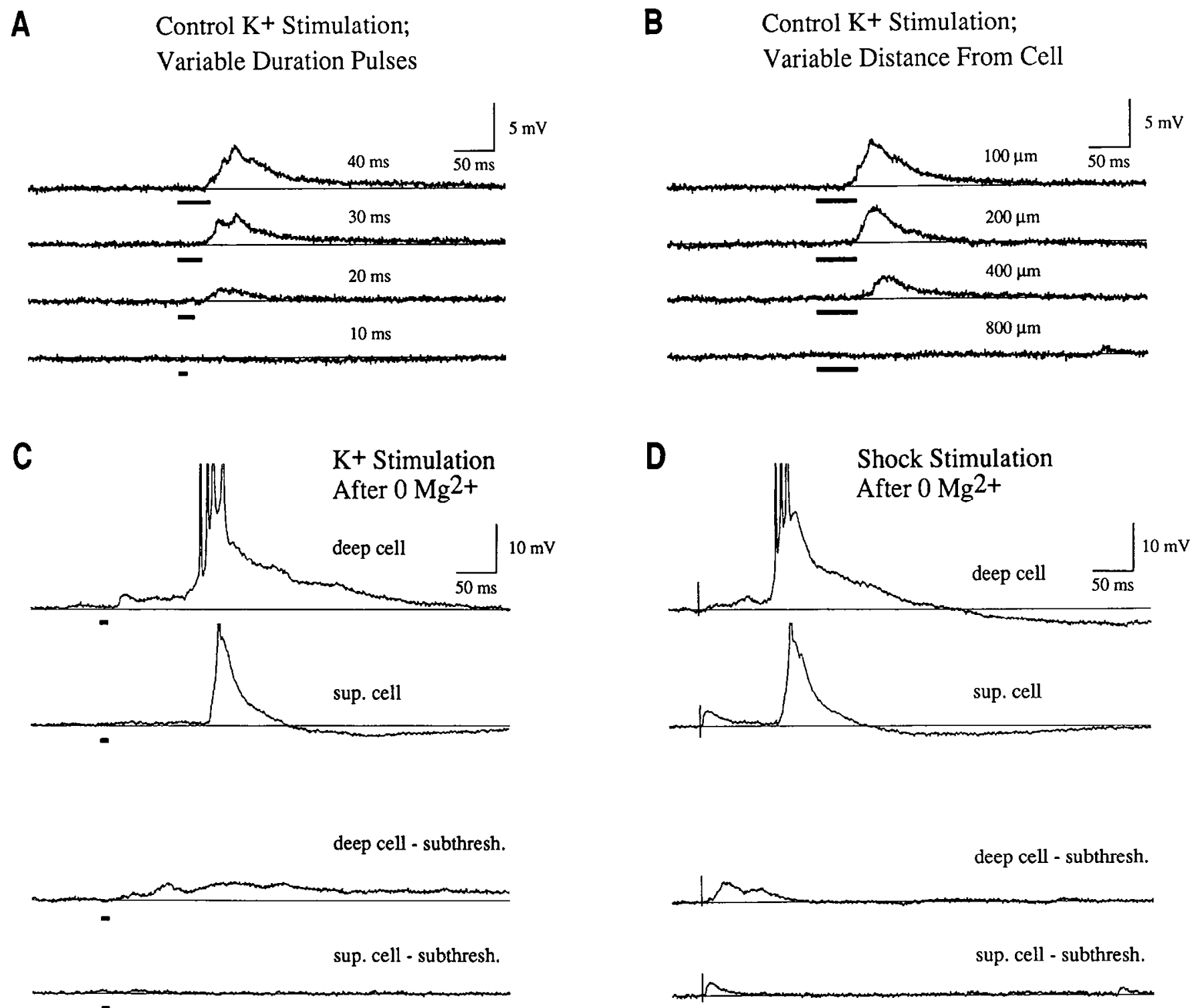

Figure 5. e-EPSPs can be evoked from the endopiriform nucleus by local elevation of external $\mathrm{K}^{+} . A$, Responses of a deep cell under control conditions to variable-duration pulses of $100 \mathrm{mM} \mathrm{KCl}$ delivered through a micropipette. Both recording and injection sites were in the endopiriform nucleus, with a separation distance of $100 \mu \mathrm{m}$. B. Same cell and conditions as in $A$, but distance of $\mathrm{K}^{+}$injection from recorded cell was varied with a constant 50 -msec pulse duration. All injection sites were within the endopiriform nucleus dorsal to the recorded cell except the site at $800 \mu m$, which was in the claustrum. Response amplitudes were graded with pulse duration and distance. $C$, Responses of simultaneously recorded deep and superficial (sup.) cells to pressure injection of $\mathrm{K}^{+}$into the endopiriform nucleus after induction of e-EPSPs by transient exposure to $0 \mathrm{Mg}^{2+}$ (different slice than in $A$ and $B$ ). Pulse duration was at threshold for the evoked e-EPSP. $D$, Shock-evoked e-EPSPs in the same cell pair illustrated in $C$. Note the close similarity in e-EPSPs evoked by shock stimulation and high $\mathrm{K}^{+}$. Similar results were obtained by local injection of glutamate (not illustrated). Bars in $A-C$ indicate times of application of pressure pulses.

crease in the amplitude or slope of the initial graded EPSP. Because the records illustrated were obtained during injection of $\mathrm{Co}^{2+}$ into the endopiriform nucleus immediately deep to the impaled cell, it can be concluded that the action of $\mathrm{Co}^{2+}$ was confined to deep structures (based on the laminar distribution of dendrites of superficial pyramidal cells, initial graded EPSPs would have been attenuated by diffusion to layer $\mathrm{Ib}$ and the superficial part of layer III).

Although it was more difficult to map accurately the area of sensitivity of the e-EPSP to $\mathrm{Co}^{2+}$ than to glutamate or $\mathrm{K}^{+}$because several minutes were required to obtain blockage and recovery for each test, relatively complete maps were obtained in three slices. As with glutamate and $\mathrm{K}^{+}$, sensitivity was observed throughout the endopiriform nucleus, but not from sites within layers I, II, or III of the piriform cortex. Partial or complete blockage could also be obtained from the ventralmost portion of the claustrum that is adjacent to the endopiriform nucleus.

These experiments suggest that deeply placed cells are required for e-EPSP generation. The required cells appear to be concentrated in the endopiriform nucleus, but may also be found in the ventral part of the claustrum or other adjoining structures that might have been affected by diffusion of $\mathrm{Co}^{2+}$.

\section{Induction of e-EPSPs can occur in isolated deep structures}

The experiments with $\mathrm{Co}^{2+}$ injection suggest that deep cells are necessary for the generation of e-EPSPs, but do not show that 
A

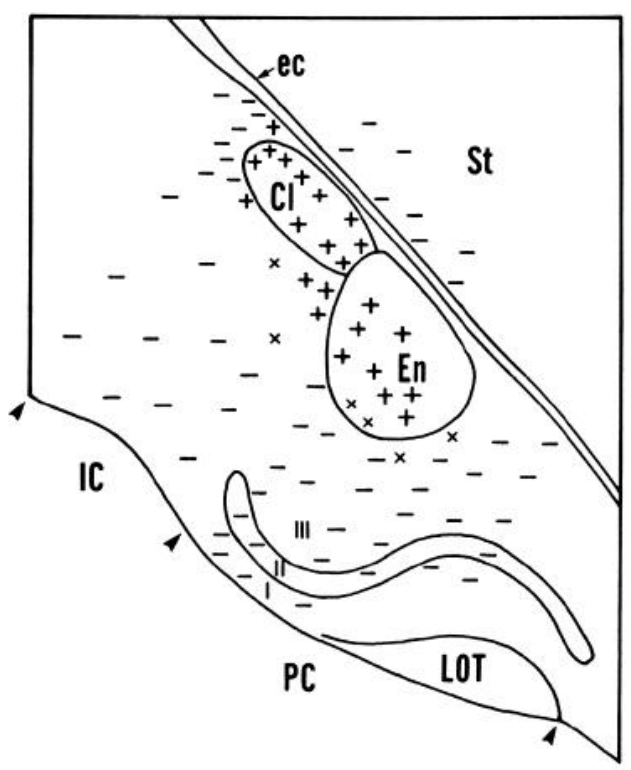

B Glutamate Injection
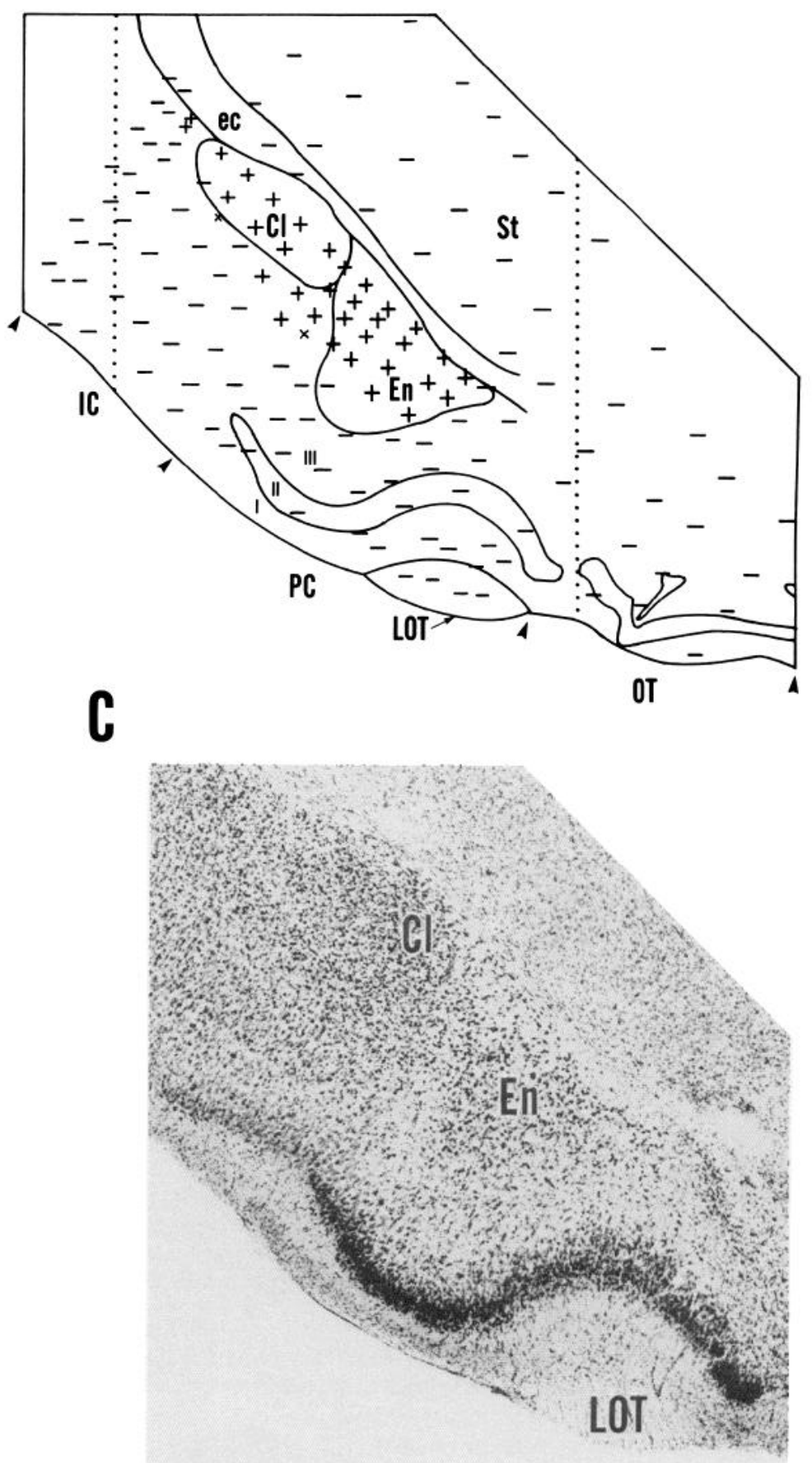

Figure 6. Maps of sites from which epileptiform EPSPs could be evoked in anterior piriform cortex by injection of $\mathrm{K}^{+}(A)$ or glutamate $(B)$. Injection was by application of pressure to micropipettes containing $100 \mathrm{~mm} \mathrm{KCl}$ or $10 \mathrm{~mm}$ L-glutamate. +, sites yielding consistent e-EPSPs; -, sites from which no responses were obtained; $\times$, sites from which e-EPSPs were inconsistently obtained. $C$, Photomicrograph of the section in $B$. The dotted lines in $B$ indicate the area of the photomicrograph. $C l$, claustrum; $e c$, external capsule; $E n$, endopiriform nucleus; $I C$, insular cortex; $L O T$, lateral olfactory tract; $O T$, olfactory tubercle; $P C$, piriform cortex; $S t$, striatum. Roman numerals denote layers in piriform cortex. Arrowheads denote boundaries between cortical areas.

they are sufficient. To determine if e-EPSPs can be induced and expressed in deep structures alone, layers I, II, and superficial III were removed from slices (Fig. 1B). An intriguing finding that complicated this experiment was that, in most of these deep fragments (12 of 14), all-or-none epileptiform potentials were present under control conditions in response to shock stimu- lation (i.e., before perfusion with $0 \mathrm{Mg}^{2+} ;$ Fig. $8 A$ ). In several slices such potentials were observed to occur spontaneously.

In two slice fragments containing only deep structures, graded synaptic responses to deep stimulation similar to those observed in intact slices could be obtained under control conditions (Fig. $8 B$, top trace). In these slices, bursting in $0 \mathrm{Mg}^{2+}$ induced 


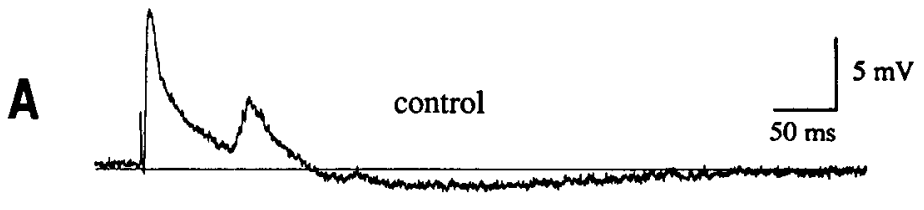

B
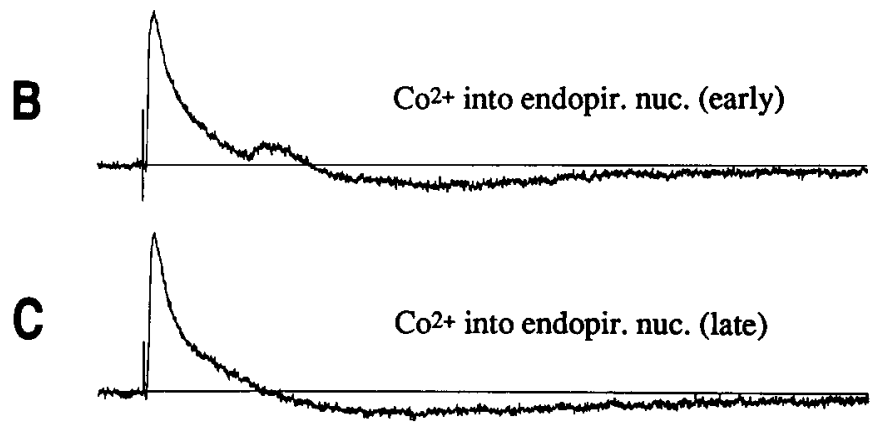

D

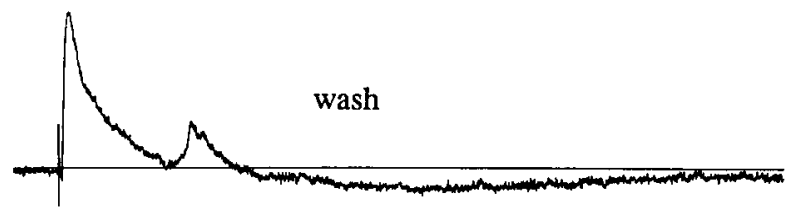

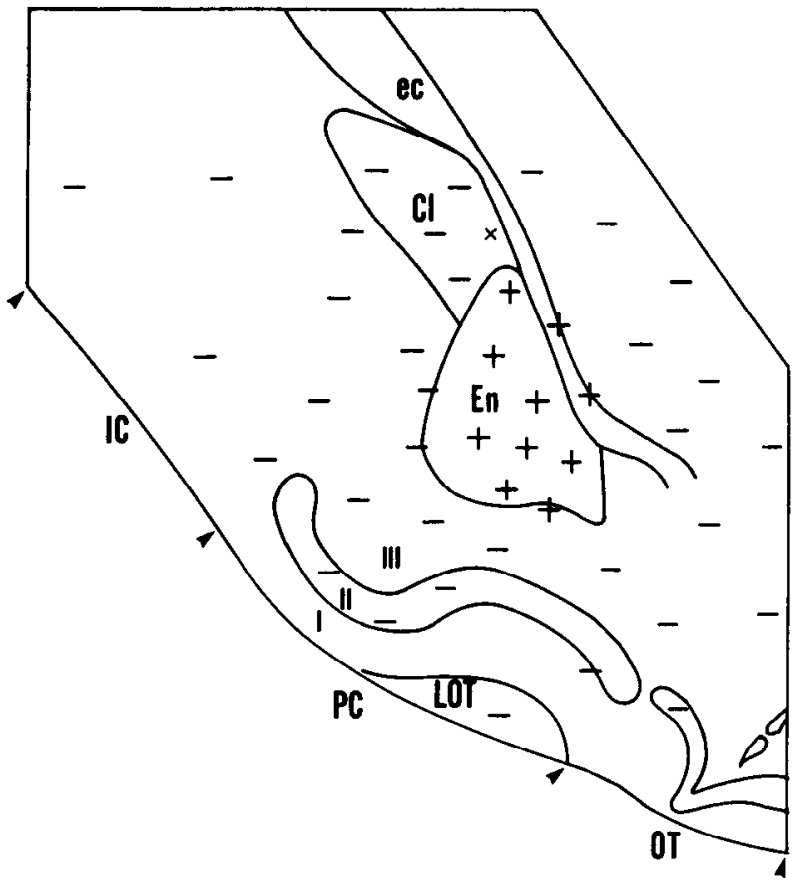

Figure 7. Blockage of e-EPSPs by injection of $\mathrm{Co}^{2+}$ into the endopiriform nucleus. $A$, Response of a superficial pyramidal cell to shock stimulation of layer Ib in normal bathing medium after induction of an e-EPSP by bursting in $0 \mathrm{Mg}^{2+}$. $B$, Response following the initiation of Co ${ }^{2+}$ injection into the endopiriform nucleus. Injection was by application of pressure pulses to a micropipette containing $10 \mathrm{~mm}^{\mathrm{C}} \mathrm{CoCl} \mathrm{l}_{2} \mathrm{C}, \mathrm{Response}$ after further injection of $\mathrm{Co}^{2+}, D$, Response $4 \mathrm{~min}$ after termination of $\mathrm{Co}^{2+}$ injection. Note the initial decline in amplitude, then blockage of e-EPSP generation during $\mathrm{Co}^{2+}$ injection without decrement of the initial graded EPSP. Map at right indicates sites from which blockage of e-EPSPs could be obtained with $\mathrm{Co}^{2+}$ injection. + , sites where blockage was consistently obtained; - , sites from which no effects were observed; $\times$, sites from which consistent decreases in amplitude or increases in latency of e-EPSPs could be obtained without a complete block. Abbreviations are the same as in Figure 6.

e-EPSPs on return to normal bathing medium, as in intact slices (Fig. $8 B$, bottom trace). These results indicate that burstinginduced changes can occur in deep cells, and that the circuitry in deep structures is sufficient for expression of the resulting eEPSPs.

\section{Induction of e-EPSPs following exclusion of the endopiriform nucleus}

An important question is whether the endopiriform nucleus is the only site capable of generating e-EPSPs, or whether it is simply the region of lowest threshold for their initiation. The finding that the excitable cells that are concentrated in the endopiriform nucleus are also found in the adjoining deep part of layer III of piriform cortex (Tseng and Haberly, 1989a) suggests that this region could also be involved in e-EPSP generation. To test this hypothesis, slice segments with and without the endopiriform nucleus were examined. In the ventral part of bisected slices that contained all layers of piriform cortex but not the endopiriform nucleus (Fig. 1D), ${ }^{1}$ e-EPSPs could be consistently induced ( $n=5$; not shown). In contrast, in slice segments from which both the deep part of layer III and the endopiriform nucleus were removed (Fig. $1 C$ ), e-EPSPs could not be induced $(n=5)$. Absolute sizes of the latter segments were

\footnotetext{
In these slice segments, the entire cytoarchitectonically distinct portion of the endopiriform nucleus was removed. Krettek and Price (1977) have introduced the term "ventral endopiriform nucleus" for an indistinct ventral region that has certain similarities in projections to the traditional endopiriform nucleus. However, the fact that e-EPSPs could not be evoked from this region by $\mathrm{K}^{+}$or glutamate suggests that it differs from the endopiriform nucleus in local connections or other factors.
}

approximately the same as the olfactory portions of perpendicular slice segments and deep fragments in which e-EPSPs did occur.

\section{Role of the endopiriform nucleus in generation of ictal-like activity}

In greater than $90 \%$ of slices, ictal-like responses were recorded during perfusion with $0 \mathrm{Mg}^{2+}$ (Fig. 9). These responses were very long in duration (Fig. 9AI) and resembled activity that occurs in the cerebral cortex during seizures (Ayala et al., 1970). Ictallike activity consisted intracellularly of an initial high-amplitude, long-duration depolarization with superimposed rhythmic fluctuations, in both pyramidal cells in the piriform cortex and cells in the endopiriform nucleus. Simultaneously recorded extracellular potentials revealed the synchronous nature of these responses (Fig. 9A2,3). When stimulation rate was $1 / 6 \mathrm{~Hz}$, only the initial response was ictal-like in most slices (Fig. $9 B$; see also Fig. 2C). However, when stimulation was discontinued for several minutes, ictal-like activity could again be evoked.

To determine if deep structures are involved in generation of ictal-like activity, responses were recorded in slice fragments during perfusion with $0 \mathrm{Mg}^{2+}$. In the ventral part of bisected slices that lacked the endopiriform nucleus (Fig. $1 D$ ), prolonged afterdischarges were never observed in $0 \mathrm{Mg}^{2+}(n=5$; Fig. $9 C)$. Moreover, no ictal-like activity was observed in superficial slice segments that included layers I through superficial III of the dorsal part of piriform cortex, but no endopiriform nucleus ( $n$ $=7$; see Fig. $1 C$ ). In contrast, ictal-like responses were observed in the two slice segments containing only the deep part of layer III and the endopiriform nucleus that did not show epileptiform 


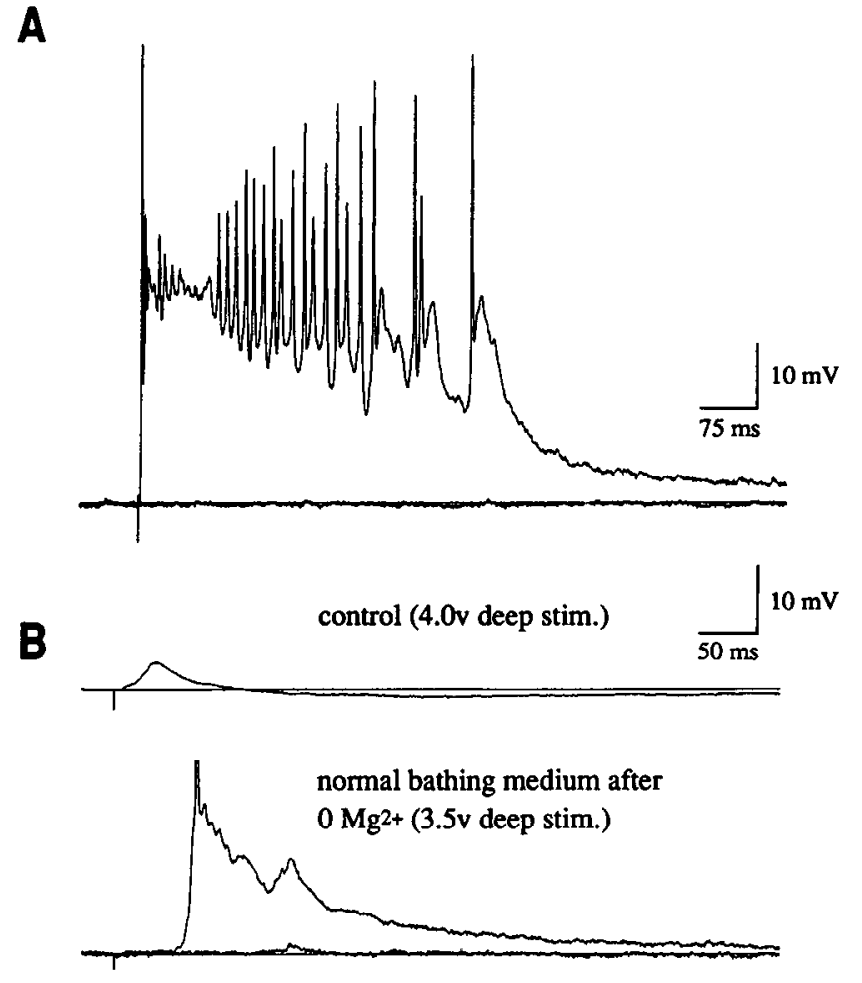

Figure 8. Cells in isolated deep structures can display epileptiform activity, including bursting-induced e-EPSPs. $A$, Superimposed responses sub- and suprathreshold for a high-amplitude burst response recorded under control conditions (i.e., no exposure to $0 \mathrm{Mg}^{2+}$ ) in a deep cell from a slice with layers I, II, and superficial III trimmed away. Threshold stimulus strength was so low that virtually no synaptic response could be detected in subthreshold traces. $B$, Although most deep slice segments displayed epileptiform responses under control conditions as shown in $A$, normal graded responses were observed in two slices as illustrated by the top trace. After exposure to $0 \mathrm{Mg}^{2+}$ and return to normal bathing medium, e-EPSPs were evoked (bottom traces; suband suprathreshold responses are superimposed). As in $A$, threshold was so low that virtually no early synaptic component was observed in subthreshold responses. All responses in $A$ and $B$ were evoked by shock stimulation in the endopiriform nucleus.

activity under control conditions. These findings suggest that the endopiriform nucleus may play a central role in the generation of both interictal-like and ictal-like activity.

\section{Discussion}

The present results suggest that deeply placed-cells drive the persistent e-EPSPs that were previously observed in superficial pyramidal cells in piriform cortex after bursting (Hoffman and Haberly, 1989). Supporting evidence includes higher amplitudes of e-EPSPs in deep than in superficial cells, triggering of action potentials by e-EPSPs in deep cells before onset of e-EPSPs in superficial pyramidal cells, occurrence of e-EPSPs in deep cells alone in perpendicular slice strips, and the induction of e-EPSPs in isolated deep portions of slices, but not in fragments containing only superficial layers. Moreover, injection of very small amounts of glutamate or $\mathrm{K}^{+}$into the endopiriform nucleus, but not the overlying cortex, consistently evoked e-EPSPs, whereas injection of $\mathrm{Co}^{2+}$ blocked their occurrence without affecting the initial graded EPSP in overlying superficial pyramidal cells.

Evidence was also obtained that the claustrum may be involved in e-EPSP initiation or generation. Although studies with slice fragments from which it was excluded show that it is not essential for their occurrence, e-EPSPs could be consistently triggered by injection of $\mathrm{K}^{+}$and glutamate into this structure. Some degree of blockage of e-EPSPs could also be obtained by injection of $\mathrm{Co}^{2+}$ into the ventralmost portion of the claustrum, though the possibility that this was a result of diffusion to the adjoining endopiriform nucleus cannot be ruled out.

Previous studies of the endopiriform nucleus have revealed that it is reciprocally connected with the overlying piriform cortex (Haberly and Price, 1978; Haberly and Presto, 1986) and that it is excited by stimulation of association fibers in piriform cortex (Tseng and Haberly, 1989a). Furthermore, a population of spiny multipolar cells has been identified in this nucleus with properties that could promote the observed long-latency epileptiform potentials (Tseng and Haberly, 1989a,b). These include a lower action potential threshold than superficial cells, the presence of small all-or-none EPSP components at long latency in synaptically mediated responses, a striking facilitation in occurrence of these late EPSPs in response to paired shocks, and the existence of membrane currents with the capacity for mediation of slow regenerative potentials and rhythmic bursting. In addition, anatomical study of these cells (Tseng and Haberly, 1989a) revealed local axon collaterals that could be the substrate for positive feedback interactions that have been postulated to underlie certain forms of epileptiform activity (e.g., Johnston and Brown, 1981; Peters and Kara, 1985; Traub et al., 1985; Traub and Dingledine, 1990).

Although the present results provide the most direct evidence for participation of the endopiriform nucleus and adjoining portion of the claustrum in e-EPSP initiation, cells in the deep part of layer III of piriform cortex may also be involved. Cells in this layer exhibit high-amplitude e-EPSPs like those observed in the endopiriform nucleus. Previous study (Tseng and $\mathrm{Ha}-$ berly, 1989a,b) has also revealed that spiny multipolar cells in the deep part of layer III are very similar both physiologically and morphologically to those in the endopiriform nucleus; that is, they also have properties that could underlie or promote generation of epileptiform activity. The observation that e-EPSPs could be induced in ventral slice segments that lack endopiriform nucleus but contain all layers of piriform cortex, but could not be induced in slices from which all deep cells had been removed, indicates that cells in deep layer III contribute to the generation of e-EPSPs. Lack of blockage by $\mathrm{Co}^{2+}$ or initiation by glutamate or high $\mathrm{K}^{+}$in layer III could be explained by the much lower density of cells in this layer than in the endopiriform nucleus (Fig. 6B,C).

A potentially puzzling question is why comparatively weak shock stimulation in superficial layers (I, II, and superficial III) consistently triggers e-EPSPs, while excitation of superficial pyramidal cells by glutamate or $\mathrm{K}^{+}$does not. Although superficial pyramidal cells synapse on and presumably excite cells in layer III and the endopiriform nucleus (Haberly and Presto, 1986), a relatively small number would be activated by glutamate or $\mathrm{K}^{+}$ injections from micropipettes, so that excitatory drive onto deep structures is presumably insufficient for triggering the generation of epileptiform activity. In contrast, shock stimulation excites association fibers that extend for long distances in layers I and III and give rise to numerous synapses that would orthodromically excite cells over a broad area, including those in the endopiriform nucleus. In addition, shock stimulation would antidromically excite cells in the endopiriform nucleus and layer III (see Tseng and Haberly, 1989a). 
A 2

1

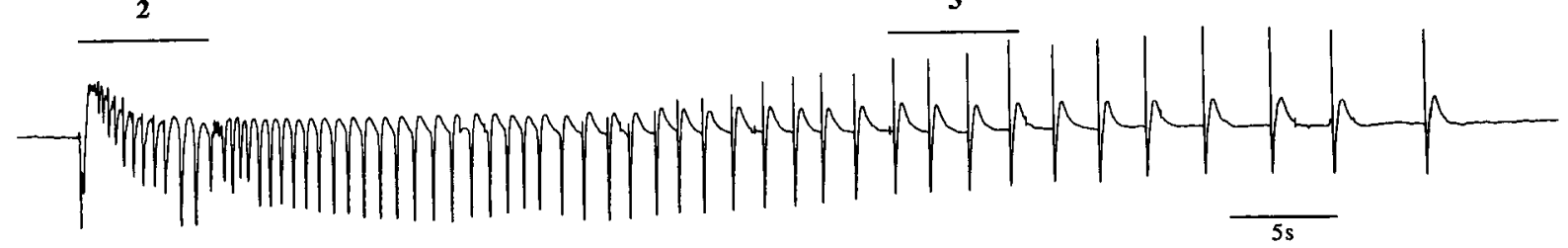

3

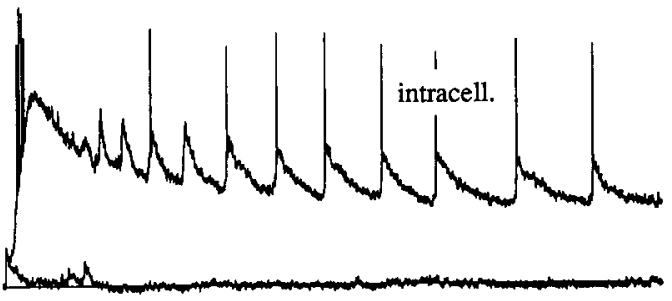

3
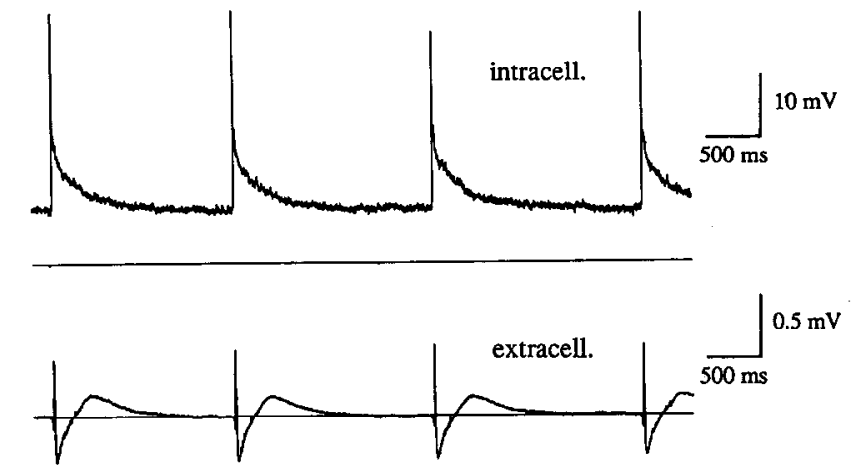
$0.5 \mathrm{mV}$ extracell.

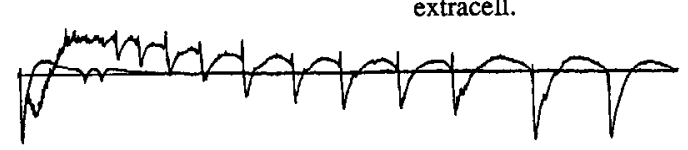

B

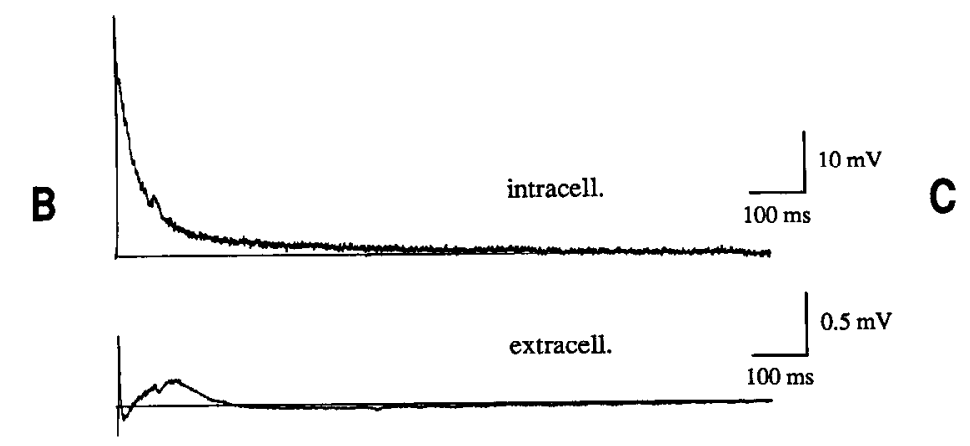

2

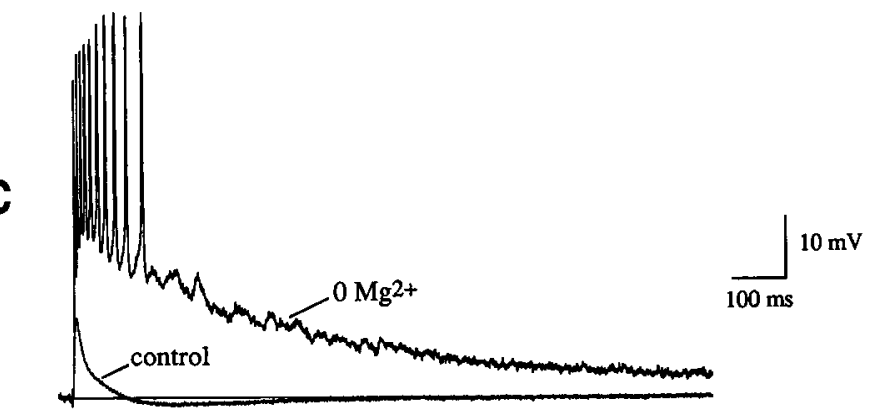

Figure 9. Ictal-like activity is evoked by $0 \mathrm{Mg}^{2+}$ in intact slices, but not in slice segments lacking endopiriform nucleus. $A$, Sustained ictal-like activity evoked by shock stimulation to layer III during perfusion with $0 \mathrm{Mg}^{2+}$ bathing medium. $A 1$, Extracellular recording from endopiriform nucleus with slow time base. $A 2$ and $A 3$, Simultaneous extracellular recording as in $A 1$ and intracellular recording from a cell in the endopiriform nucleus. The calibration bars in $A 3$ also apply to $A 2$. Extracellular records correspond to the numbered bars above the recording in $A 1$. The response to an identical stimulus recorded $6 \mathrm{sec}$ before the ictal-like activity was evoked is superimposed in $A 2$. $B$, Simultaneous intra- and extracellular recordings of an interictal-like burst obtained during $1 / 6 \mathrm{~Hz}$ stimulation in $0 \mathrm{Mg}^{2+}$ after termination of the initial sustained ictal-like response (same cell as in $A$ ). Note the lack of rhythmic discharges and much shorter duration (time base is faster than in $A$ ). $C$, Superimposed responses of a superficial cell to layer $\mathrm{Ib}$ stimulation under control conditions and during perfusion with $0 \mathrm{Mg}^{2+}$ bathing medium in a slice of ventral piriform cortex containing no endopiriform nucleus. Slices lacking the endopiriform nucleus consistently failed to display ictal-like activity.

Although the present study was not designed for identification of the change or changes induced by bursting that underlie e-EPSP initiation, the results do provide possible insight into the circuitry interactions that are involved in their generation. The primary relevant observation is that, when the number of active cells in the endopiriform nucleus was decreased by injection of $\mathrm{Co}^{2+}$ (Fig. 7) or slice dissection (Fig. 4), the amplitudes of e-EPSPs were decreased in both deep and superficial cells. One possible explanation for this observation is that positive feedback interactions via excitatory interconnections contribute to e-EPSP generation, as modeled for hippocampus (Traub and Wong, 1983; Wong and Traub, 1983; Traub et al., 1985, 1987; Traub and Dingledine, 1990), and that the interconnections between cells in the endopiriform nucleus and their projections to superficial pyramidal cells are highly distributed spatially. In such a network, each cell would receive excitatory drive from nearby and distant cells so that removal of a part of the poot of active cells would decrease e-EPSP amplitude in all cells. From the dissection experiments (Fig. $8 \mathrm{~B}$ ), it can also be concluded that circuit interactions between the endopiriform nucleus and superficial layers of piriform cortex are not required for e-EPSP generation. Bascd on the finding that e-EPSPs can be triggered at brief latency by very small amounts of injected glutamate and $\mathrm{K}^{+}$, it would appear that the postulated positive feedback interactions can be initiated by activity in a small number of cells. However, failure of current-evoked action potentials in individual deep cells to trigger e-EPSPs (Hoffman and Haberly, unpublished observations) indicates that this number is usually greater than 1 (cf. Miles and Wong, 1983).

e-EPSPs induced by bursting activity in the piriform cortex closely resemble bursting-induced potentials in the hippocampus. Ben-Ari and Gho (1988) have reported that bursting in- 
duced in slices of rat hippocampus by perfusion with kainic acid or high potassium was followed, upon return to normal bathing medium, by the persistent appearance of long-latency EPSPs in the CA3 region. Like e-EPSPs observed in the deep layers of piriform cortex, these EPSPs were high in amplitude (evoking short bursts of action potentials), all-or-none in occurrence, accompanied by extracellular field potentials, and dependent on the activation of NMDA receptors during the induction process but not for their continued presence after bursting. Preliminary results obtained in this laboratory (Hoffman and Haberly, unpublished observations) suggest that epileptiform potentials very similar to e-EPSPs can be induced by bursting activity in neocortex, both in slices containing piriform cortex and in isolated neocortex.

An incidental observation with implications for epileptogenesis is that horizontal cuts through layer III of piriform cortex oriented parallel to the cortical surface result in high-amplitude, spontaneous and shock-evoked epileptiform potentials in the deep but not superficial portions of slices (Fig. $8 A$ ). Similar but smaller potentials were also frequently observed in slices in which single cuts oriented perpendicular to the cortical surface passed through the endopiriform nucleus (Hoffman and $\mathrm{Ha}$ berly, unpublished observations). One possible mechanism for these effects is the interruption of inhibitory circuitry. For example, loss of inhibition from superficially placed cells onto deep cells or loss of excitatory drive from superficial pyramidal cells onto deep inhibitory interneurons could contribute (see Haberly et al., 1987; Sheldon and Aghajanian, 1990). Cuts parallel to the cortical surface would completely interrupt such pathways; perpendicular cuts on three sides (original Vibratome cuts and secondary cut) could interrupt a substantial part of obliquely oriented laminar connections such as deeply directed axon collaterals of superficial pyramidal cells (e.g., Haberly and Bower, 1984, their Fig. 7). The lack of epileptiform potentials under control conditions in narrow perpendicular slice strips (Fig. 4) may result from the limited capacity for excitatory feedback interactions in such small fragments.

Alternatively, epileptiform activity induced by secondary cuts may result from additional damage to slices associated with such procedures. This possibility seems less likely because all cuts (both Vibratome and secondary) were carried out in rapid sequence under the same conditions of temperature and oxygenation. Moreover, epileptiform potentials associated with secondary cuts appeared to require the presence of the endopiriform nucleus, because they did not occur under control conditions in slice segments containing only ventral piriform cortex or superficial layers.

The effect of secondary cuts also provides a possible explanation for the intense bursting activity reported by McIntyre and Wong (1986) in slices from piriform cortex of normal rats under control conditions - an observation not corroborated by in vitro or in vivo studies from other laboratories. The close resemblance of the burst potentials reported by McIntyre and Wong to those obtained in the present study after removal of superficial layers suggests that the bursting they observed may have been a consequence of superficial damage resulting from stripping of the pia that was carried out before slices were cut. This result also indicates that care must be taken when trimming slices to isolate structures adjacent to the piriform cortex (e.g., the amygdala or neocortex), because cuts through the piriform cortex or the endopiriform nucleus could induce epileptiform activity that could propagate to the areas of interest.
An important question is whether the area of initiation of e-EPSPs delineated in the present study in vitro overlaps with the areas in "deep piriform cortex" from which generalized seizures are evoked by injection of convulsant drugs (Piredda and Gale, 1985; Stevens et al., 1988) or from which blockage of kindling and kindled seizures is obtained from injection of excitatory amino acid antagonists (Croucher et al., 1988) or the GABA transaminase inhibitor $\gamma$-vinyl-GABA (Stevens et al., 1988 ) in studies in vivo. The present data are not adequate to determine the extent of correspondence in the anterior-posterior dimension, but there is a close correspondence between the present maps obtained in vitro and those generated by Stevens and coworkers (Stevens et al., 1988) both for generation of seizures by injection of bicuculline and blockage of kindled seizures by $\gamma$-vinyl-GABA. In maps generated by Piredda and Gale (1985) and Croucher and coworkers (Croucher et al., 1988), the most sensitive areas were somewhat more ventrally placed than in the present study or the study of Stevens and coworkers. However, because injection cannulas were placed stereotaxically in the frontal plane in the in vivo studies, they would have passed close to or through the endopiriform nucleus and claustrum. Therefore, this discrepancy could have been a consequence of backflow during injection.

Physiological and anatomical evidence, taken together, suggests that the endopiriform nucleus may play a role in generation of certain types of seizures. Of particular relevance is the present observation that this structure can generate prolonged ictal-like as well as interictal-like activity. Because the endopiriform nucleus projects to the overlying piriform cortex that, in turn, gives rise to heavy direct projections to the entorhinal cortex, amygdala, and insular and orbitofrontal areas of neocortex (Luskin and Price, 1983; Price, 1985; Takagi, 1986), epileptic activity originating in this structure could spread throughout the forebrain, thereby accounting for the rapid generalization of seizures observed with injection of convulsants into the vicinity of the deep piriform cortex. The observation that appropriately placed cuts through the piriform cortex or the endopiriform nucleus can induce epileptiform activity may also be relevant to understanding the initiation of "uncinate seizures" that are often associated with tumors involving olfactory structures in the uncinate gyrus (Jackson and Beevor, 1890).

\section{References}

Ayala GF, Matsumoto H, Gumnit RJ (1970) Excitability changes and inhibitory mechanisms in neocortical neurons during seizures. J Neurophysiol 33:73-85.

Ben-Ari Y, Gho M (1988) Long-lasting modification of the synaptic properties of rat CA3 hippocampal neurons induced by kainic acid. J Physiol (Lond) 404:365-384.

Christian EP, Dudek FE (1988) Characteristics of local excitatory circuits studied with glutamate microapplication in the CA3 area of rat hippocampal slices. J Neurophysiol 59:90-109.

Croucher MJ, Bradford HF, Sunter DC, Watkins JC (1988) Inhibition of the development of electrical kindling of the prepyriform cortex by daily focal injections of excitatory amino acid antagonists. Eur J Pharmacol 152:29-38.

Haberly LB, Bower JM (1984) Analysis of association fiber system in piriform cortex with intracellular recording and staining techniques. J Neurophysiol 51:90-112.

Haberly LB, Presto S (1986) Ultrastructural analysis of synaptic relationships of intracellularly stained pyramidal cell axons in piriform cortex. J Comp Neurol 248:464-474.

Haberly LB, Price JL (1978) Association and commissural fiber systems of the olfactory cortex of the rat. I. Systems originating in the piriform cortex and adjacent areas. J Comp Neurol 178:711-740.

Haberly LB, Hansen DJ, Feig SL, Presto S (1987) Distribution and 
ultrastructure of neurons in opossum piriform cortex displaying immunoreactivity to GABA and GAD and high-affinity tritiated GABA uptake. J Comp Neurol 266:269-290.

Hoffman WH, Haberly LB (1987) Development of an all-or-none depolarizing potential after bursting activity in piriform cortex: a possible model for the kindling phenomenon. Soc Neurosci Abstr 13: 1101.

Hoffman WH, Haberly LB (1988) The deep piriform cortex is the site of generation for long-latency EPSPs induced by bursting activity. Soc Neurosci Abstr 14:278.

Hoffman WH, Haberly LB (1989) Bursting induces persistent all-ornone EPSPs by an NMDA-dependent process in piriform cortex. J Neurosci 9:206-215.

Jackson JH, Beevor CE (1890) Case of tumour of the right temporosphenoidal lobe bearing on the localisation of the sense of smell and on the interpretation of a particular variety of epilepsy. Brain 12: 346-357.

Johnston D, Brown TH (1981) Giant synaptic potential hypothesis for epileptiform activity. Science 211:294-297.

Krettek JE, Price JL (1977) Projections from the amygdaloid complex to the cerebral cortex and thalamus in the rat and cat. J Comp Neurol 172:687-722.

Luskin MB, Price JL (1983) The topographic organization of associational fibers of the olfactory system in the rat, including centrifugal fibers to the olfactory bulb. J Comp Neurol 216:264-291.

McIntyre DC, Wong RKS (1986) Cellular and synaptic properties of amygdala-kindled pyriform cortex in vitro. J Neurophysiol 55:12951307.

Miles R, Wong RKS (1983) Single neurones can initiate synchronized population discharge in the hippocampus. Nature 306:371-373.

Peters A, Kara DA (1985) The neuronal composition of area 17 of rat visual cortex. II. The nonpyramidal cells. J Comp Neurol 234: 242-263.

Piredda S, Gale K (1985) A crucial epileptogenic site in the deep prepiriform cortex. Nature 317:623-625.

Piredda S, Gale K (1986) Role of excitatory amino acid transmission in the genesis of seizures elicited from the deep prepiriform cortex. Brain Res 377:205-210.
Price JL (1985) Beyond the primary olfactory cortex: olfactory-reflated areas in the neocortex, thalamus and hypothalamus. Chem Senses 10: 239-258.

Racine RJ, Mosher M, Kairiss EW (1988) The role of the pyriform cortex in the generation of interictal spikes in the kindled preparation. Brain Res 454:251-263.

Sheldon PW, Aghajanian GK (1990) Serotonin (5-HT) induces IPSPs in pyramidal layer cells of rat piriform cortex: evidence for the involvement of a 5- $\mathrm{HT}_{2}$-activated interneuron. Brain Res 506:62-69.

Stevens JR, Phillips I, Beaurepaire R (1988) Gamma-vinyl GABA in endopiriform area suppresses kindled amygdala seizures. Epilepsia 29:404-411.

Takagi SF (1986) Studies on the olfactory nervous system in the old world monkey. Prog Neurobiol 27:195-250.

Traub RD, Dingledine R (1990) Model of synchronized epileptiform bursts induced by high potassium in CA3 region of rat hippocampal slice. Role of spontaneous EPSPs in initiation. J Neurophysiol 64 1009-1018.

Traub RD, Wong RKS (1983) Synchronized burst discharge in disinhibited hippocampal slice. II. Model of cellular mechanism. J Neurophysiol 49:459-471.

Traub RD, Wong RKS, Miles R, Knowles WD (1985) Neuronal interactions during epileptic events in vitro. Fed Proc 44:2953-2955.

Traub RD, Miles R, Wong RKS (1987) Models of synchronized hippocampal bursts in the presence of inhibition. I. Single population events. J Neurophysiol 58:739-751.

Tseng G-F, Haberly I.B (1988) Characterization of synaptically mediated fast and slow inhibitory processes in piriform cortex in an in vitro slice preparation. J Neurophysiol 59:1352-1376.

Tseng G-F, Haberly LB (1989a) Deep ncurons in piriform cortex. I. Morphology and synaptically evoked responses including a unique high amplitude paired shock facilitation. J Neurophysiol 62:369-385.

Tseng G-F, Haberly LB (1989b) Deep neurons in piriform cortex. II. Membrane properties that underlie unusual synaptic responses. J Neurophysiol 62:386-400.

Wong RKS, Traub RD (1983) Synchronized burst discharge in disinhibited hippocampal slice. I. Initiation in CA2-CA3 region. J Neurophysiol 49:442-458. 